\title{
Research on Optimization Strategies of Goal Programming-based Square Community Fitness Activities
}

\author{
Dayong Guo*
}

Department of Public Physical Education, Quzhou College of Technology, Quzhou 324000, China

\begin{abstract}
Community sports and physical fitness play an important role in China's sports. They exert influence on community's life and health. Currently, though China's community sports activities have experienced development, but they still face problems that need to be timely resolved. The paper conducted a comprehensive analysis of China's community sports activities, and combined goal programming with numerical analysis to carry out a quantitative research. Firstly, this proceeded with a statistical analysis of the people of China who participate in square fitness activities, and analysed the participants' physical health, social status and Chinese residents' satisfaction with different sports activities. Secondly, on this basis, by establishing objective function, goal programming was employed to establish an optimization model for China's community sports development. This model analyzed optimization strategies to propel development, reaching an optimal solution, and further observed that retired people mainly take part in community's fitness activities. Square dance and other group activities are important events that are most suitable for the development of China's community sports and fitness activities, and Chinese residents have higher satisfaction with such activities, which greatly influences China's community activities development.
\end{abstract}

Keywords: Community square fitness, Goal programming, Optimization strategies.

\section{INTRODUCTION}

In contemporary society, masses are best carriers of sports communication, and also represent strength to develop sports activities. Masses positive participation in community square dances has greatly developed community square dance. However, Chinese' fitness still has lots of problems and there are many factors that restrict China's community activities development. Among them, which exercise should be chosen by community fitness is one of the main factors [1].

Lu Chen conducted a "Survey on square fitness dance development situation in community sports". He took Jishou city as an example, and conducted interviews and investigation, to obtain actual reports on square fitness through a questionnaire. He also analysed community activities development from community square dance behaviors, and put forward a series of measures regarding improving the community activities that exerted great influence on China's community activities. [2]. Wang Shao-Jiu in the article "Square fitness activities functions on coronary heart disease patients' emotions and autonomic nerve", carried out a sample survey on the number of patients suffering from coronary heart disease. By consulting considerable amount of literature, he summarized former research experiences, by utilizing logical analysis, mathematical statistics, system analysis and other methods.

*Address correspondence to this author at the Department of Public Physical Education, Quzhou College of Technology, Quzhou 324000, China; Tel: +86-13357001757; E-mails: 13357001757@qq.com
He examined important effects of square fitness activities on health, and pointed out that positive participation in community square fitness activities positively influenced coronary heart disease patients' emotional instability and their physical health to a certain degree and also ensured speedy recovery of the disease [3]. Xu Yue-Yun in the study "Jinjiang square fitness dance development in sports city construction process", employed literature, system analysis and other methods to make quantitative analysis of the current situation of square fitness activities. The study also analyseddata from statistical chart analysis, and pointed out that state should increase investment in community square, especially investment in hardware equipments. Meanwhile, it should increase awareness of square fitness activities which are suitable for different groups of people through comprehensive research, and should timely provide corresponding countermeasures and methods [4]. Shan Shan in "Square fitness dance creation theory and practice research", compared different communities' activities statuses, and studied existing problems and gaps in different regions' square activities and concluded that Chinese square dance suffered from multiple factors' influences that resulted in uneven development. There is a huge gap observed between square dance in city and village, especially in rural sports where development in this field was rather backward. to deal with problem, the state should make reforms in square activities in villages and towns to better impel China's square activities development [5].

The paper utilized mathematical comparative analysis approach and goal programming, establishing a mathematical model to evaluate Chinese square community activities 
development and optimization strategies. On the basis of analysis and research, the study examined different square community activities in different cities, and focused on most suitable activities for different groups of people along with fitness equipments as these are the factors that can maximize the benefits of square activities and can achieve the purpose of serving people.

\section{COMMUNITY SQUARE FITNESS CURRENT SIT- UATION}

Community square activities development has an impact on China's national development. Currently, there has been a drastic change in China's urban and rural community sports investment, representation and overall impact but China's community activities still have many problems, unbalanced investment, imperfect organizational structure, lack of consciousness, etc., therefore it is necessary to conduct an optimization research on community activities [6] (Fig. 1).

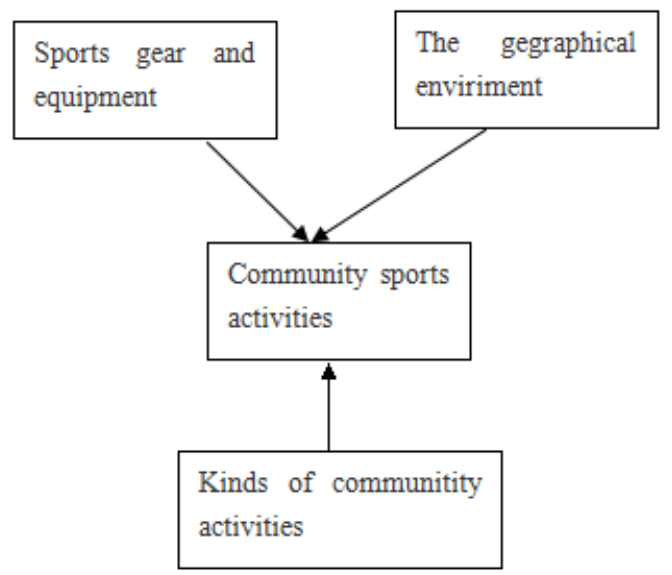

Fig. (1). The influence of community activities.

From the above Fig. (1), it is clear that factors affecting China's community square development are mainly sports gear and equipment, groups, urban and rural differences, state investment, etc. To develop efficient community sports and reduce urban and rural sports development differences, it is necessary to create sports related awareness among residents, increase government investment in public sports equipment and advertising media based on community sports field to expand the impacts on masses.

\subsection{Fitness Participants' Occupation Status}

In contemporary society, people pay more attention to health. Participants in community fitness activities have almost covered all the scopes of occupations, necessitating to find out weaknesses in community sports activities, and put forward solutions to the existing problems as well as better implement people-oriented policies (Table 1).

Table 1 shows comparative data on Chinese athletes'fitness obtained from China's statistical yearbook, general sports administration in China and internet showing relevant investigation report. The above data is used to draw the following statistical Fig. (2),to further analyze features reflected by the data.

From the above statistical Fig. (2), it was analyzed that retired people represent considerably large proportion, which conforms to China's increased aging, and also to the fact that old people have more leisure time, and due to poor physical immunity, they need exercise for a healthy life. In comparison, state civil servants and scientific research personnel represent around total $20 \%$ proportion. The data reminds that though these people also have fixed working time, they do not take initiative for square activities fitness in their spare time which creates health issues. Therefore, the investigation result suggests such people to pay attention to exercise in their leisure time.

\subsection{Chinese Residents' Sports Fitness Consciousness}

There are a number of factors restricting development in community activities such as, economic factors, regional factors, infrastructure construction and others. Sports

Table 1. Fitness participant occupation.

\begin{tabular}{|c|c|c|c|c|c|}
\hline Group of people & Retired People & Civil Servants & $\begin{array}{c}\text { Scientific Research } \\
\text { Personnel }\end{array}$ & Farmers & Students \\
\hline \hline Proportion\% & $44.54 \%$ & $11.3 \%$ & $13.75 \%$ & $12.04 \%$ & $10.32 \%$ \\
\hline
\end{tabular}

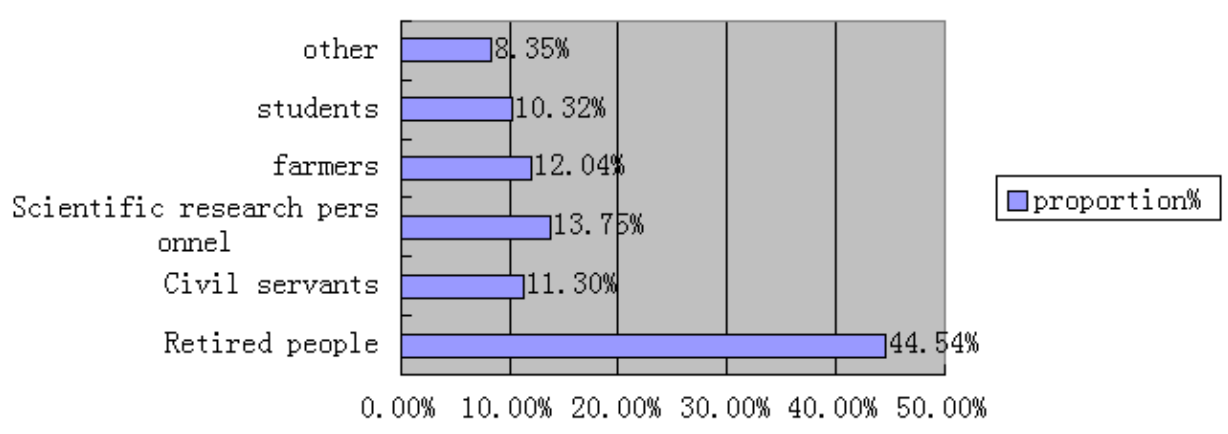

Fig. (2). Professional fitness participants. 
Table 2. Chinese residents' sports fitness consciousness survey.

\begin{tabular}{|c|c|c|c|c|}
\hline Thought & Labor is the Fitness & $\begin{array}{c}\text { Have no Disease or } \\
\text { Health }\end{array}$ & A Waste of Time & $\begin{array}{c}\text { Sports Fitness Propels to Physical } \\
\text { and Psychological Health }\end{array}$ \\
\hline \hline Percentage(\%) & $13 \%$ & $7 \%$ & $10 \%$ & $70 \%$ \\
\hline
\end{tabular}

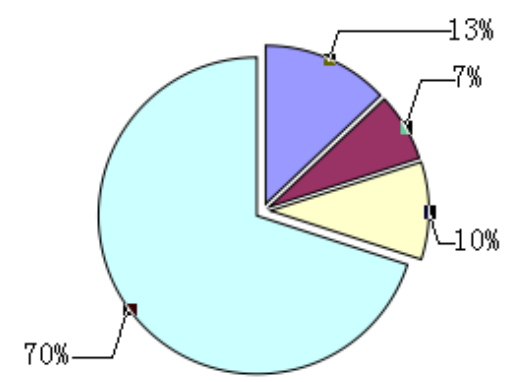

$\square$ Labor is the fitness
$\square$ Have no disease or heal
th
$\square$ A waste of time
$\square$ Fitness

Fig. (3). The sport consciousness of residents in our country.

Table 3. Chinese community fitness activities participants' health conditions.

\begin{tabular}{|c|c|c|c|c|c|}
\hline Health conditions & Health & Good & General & Weaker & Poor \\
\hline \hline Proportion & $35 \%$ & $33 \%$ & $28 \%$ & $2 \%$ & $2 \%$ \\
\hline
\end{tabular}

consciousness is also a key factor that affects its development. Sports involves activities that ensure mass relaxation, entertainment and physical exercise. Research on the differences in community activities fitness consciousness has proved helpful to find out problems and put forward corresponding solutions by combining urban and rural development situations targeted at the problems (Table 2).

Table 2 shows contrastive data regarding China's community square fitness consciousness survey, in which the percentage reflects mass with different sports fitness consciousness proportions in the number of Chinese residents. The data was collected from Chinese statistical yearbook, general sports administration of China and the relevant investigation report on the internet. Based on the above data, the following statistical Fig. (3) was drawn, and the data was compared for further analysis of residents' fitness consciousness.

From the above pie Fig. (3), it is clear that Chinese residents' community fitness consciousness is stronger. People who think sports fitness could propel physical and psychological health were observed to be around $70 \%$, while only $10 \%$ people showed no recognition of sports fitness. Moreover, people with this view that labor can replace sports fitness were around $13 \%$, and the ones having no disease or were healthy were very few, and some were of the view that sports is a waste of time. Though $70 \%$ Chinese residents were of the view that sports fitness has an impact on physical and psychological health, nearly half of the total sample's population still was of the view that sports fitness is useless and is a waste of time. This has hindered the spread of community sports in the whole nation to a great extent, and has puts forward worthy recommendations to be adopted to improve overall health.

\subsection{Chinese Community Fitness Activities Participants' Health Conditions}

Table 3 shows health conditions of participants in Chinese community fitness activities. The data was collected from Chinese statistical yearbook, general sports administration of China and the relevant investigation report on the internet. Statistical analysis was carried out using statistical Table 3, for making further conclusions:

From the statistical Fig. (4), following conclusions are drawn:

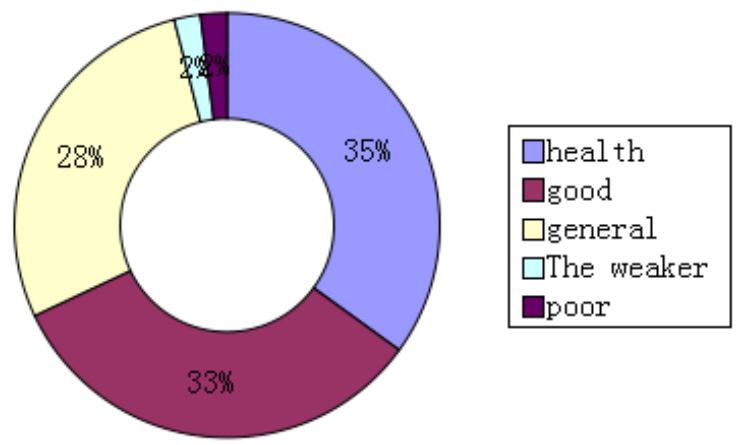

Fig. (4). The health of the community fitness activities in China.

The above statistical Fig. (4) indicates that healthy body mass, people with good physique, and with moderate physique respectively represented around one third of the population Improvement in living standards lead to a healthy life style ensuring a healthy old age Therefore to further advance the development of sports fitness in China, the state needs to utilize every possible means for the publicity of sports activities. 
Table 4. Square activities different ways proportions.

\begin{tabular}{|c|c|c|c|c|c|c|}
\hline Item & Sports Equipment & Jogging & Tai Ji & Sword Dancing & Square Dance & Others \\
\hline \hline Group of people & $26 \%$ & $25.8 \%$ & $4.0 \%$ & $3.7 \%$ & $36.2 \%$ & $3.8 \%$ \\
\hline
\end{tabular}

Table 5. Square activities different ways comparison.

\begin{tabular}{|c|c|c|c|c|c|c|c|c|}
\hline Item & Park Square & Activity Place & $\begin{array}{l}\text { Unit Sports } \\
\text { Ground }\end{array}$ & $\begin{array}{c}\text { Community } \\
\text { Clearing }\end{array}$ & $\begin{array}{l}\text { One's Own } \\
\text { Courtyard }\end{array}$ & Street & School Stadium & Others \\
\hline Group of people & $54.81 \%$ & $39.96 \%$ & $36.40 \%$ & $28.45 \%$ & $6.07 \%$ & $4.81 \%$ & $21.34 \%$ & $3.56 \%$ \\
\hline
\end{tabular}

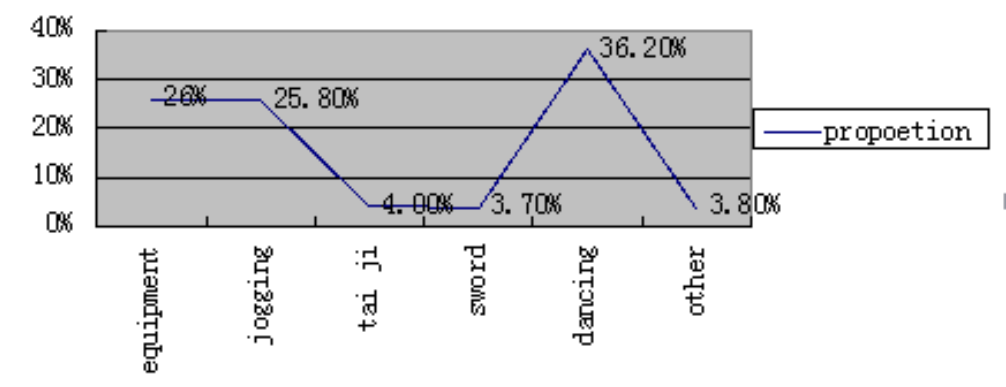

Fig. (5). Square contrast activity different ways.

\subsection{Chinese Square Activities Different Ways}

Participation in community sports activities is influenced by organizational influences. In general, community sports fitness organizational activities are diversebased on varying interests, habits, physical health conditions, living and social environments, which facilitate selection of suitable sports fitness activities to achieve health demands (Table 4).

Table 4 shows the proportion of China's square activities, based on the data obtained from Chinese statistical yearbook, general administration of sport of China and relevant investigation reports available on the internet. Based on the data listed in the above table, statistical analysis was carried out to draw pie charts about urban sports activities organizational way and rural sports activities organizational way to better develop China's community sports fitness activities.

From the analysis of broken line in Fig. (5), the conclusion is drawn that in China's community sports fitness activities, community square dance occupies great proportion of around $40 \%$, and the number is still increasing Square dance is a kind of collective dance in which everyone gathers together not only to keep fit through exercise, but also chat, relieve boredom and divert themselves to nurture good interpersonal relationships. A small proportion is however into sword dancing because sword dancing has technical contents that are not easy to grasp.

\subsection{China's Community Square Fitness Activities Places}

Expansion of community sports fitness activities, especially for the white-collar workers that requires devel- opment of various units, communities, schools, stadiums and sports rooms to meet the fitness demands from this group of people, which will not only serve people, but also vigorously promote and advocate contemporary Chinese demands and enforcement of policies.

Table 5 gives statistical table of China's community activity place The data was obtained from investigation report through physical education path, Chinese statistical yearbook, general administration of sport in China and the relevant investigation report on the internet.

Statistical Fig. (6) was drawn from statistical analysis method, highlighting relative conclusions about China's community square fitness activities in different ways:

Fig. (6) indicates that nearly half of the residents take part in fitness activities in the Park square as it is a public place, attracting people of same interests to gather to bring pleasure in their life, while the proportion of those performing fitness activities is relatively small as a small number of people can afford to buy houses with courtyards.

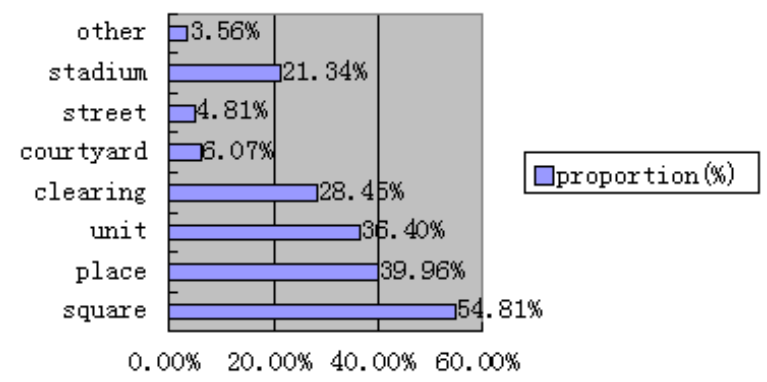

Fig. (6). Square contrast activity different ways. 


\section{CHINA'S RURAL SPORTS ACTIVITIES EVENTS}

Sports is one of the preferred choices to derive relaxation in China, with sports undergoing development and extensive expansion in fitness. However, from an overall perspective, China's sports fitness activities are though simple, yet practical. Usually the popular sports places are nonoperational are and require self-management to be operational.

According to an investigation, China's public sports fitness activities mainly include taijiquan, sword dancing, square dance, running, gymnastics, bowling, rope skipping and so on. Table 6 given below provides China's community sports activities data from general administration of sport in China and from Chinese statistical yearbook :

\subsection{Goal Programming Guiding Thought}

As the name suggests, goal programming is programming all given systematical problems by mathematical methods and further getting a group of optimal schemes of practice expected goal. Goal programming overcomes linear programming constraints that only solve a group of linear constraint conditions. In addition, certain goals in real life are primary and secondary with mutual complementation and mutual antagonism. Meanwhile, there is also a maximum value, a minimum value as well as the difference of quantitative and qualitative. LP cannot solve these problems, while goal programming just overcomes the drawback.

Generally, goal programming has three kinds of methods, weighted coefficient method, priority method and effective solution method. Among them, weighted coefficient method definesa weight on every solved goal, and further converts complicated multiple goals problems into single goal problems, but its weight rationality is hard to set; priority method is to classify each goal into different grades, with its classification evidence being each important for eachgoal. Effective solution can take all goals into account and further get the most satisfied solution.

Goal programming objective function is composed of defined corresponding priority factors according to positive and negative deviation values for various objective constraints. Its common basic form is to:

Make positive and negative deviation small, and then further arrive at a goal value:

$$
\min z=f\left(d^{+}+d^{-}\right)
$$

Make positive deviation small, ruling out the need to arrive at a goal value:

$$
\min z=f\left(d^{+}\right)
$$

Make negative deviation small, with surpass goal value and surpass quantity not limited:

$$
\min z=f\left(d^{-}\right)
$$

Among them, positive and negative deviation values are as follows:

Known that $d$ is the decision variable function, positive deviation variable $d^{+}=\max \left\{d-d_{0}, 0\right\}$ represents the part that calculation value surpasses goal regulated value; negative deviation variable $d^{-}=-\min \left\{d-d_{0}, 0\right\}$ represents the calculation value less than goal regulated value; and $d_{0}$ is $d$ goal value, which always has $d^{+} \times d^{-}=0$.

Priority factor is $P_{1}, P_{2}, \cdots$, and it has $P_{k} \gg P_{k+1}, k=1,1, \cdots, q$, which represents $P_{k}$ having greater priority than $P_{k+1}$.

Goal programming normal mathematical model is:

Known that $x_{j}(j=1,2, \cdots, n)$ is the decision variable function, it totally has $m$ pieces of rigid constraints, equality constraints or inequality constraints. It has $l$ pieces of soft goal constraints; and its goal programming constraints deviation variable is $d^{+}, d_{i}^{-}(i=1,2, \cdots, l)$. Assume that it has $q$ pieces of priorities that are respectively $P_{1}, P_{2}, P_{3}, \cdots, P_{q}$. In the same priority $P_{k}$, weights are different that are respectively $\omega_{k j}^{+}, \omega_{k j}^{-}(j=1,2, \cdots, l)$. Therefore, the general mathematical form of goal programming is:

$$
\begin{aligned}
& \min z=\sum_{k=1}^{q} P_{k}\left(\sum_{j=1}^{l}{\omega^{-}{ }_{k j} d_{j}^{-}+\omega^{+}{ }_{k j} d_{j}^{+}}^{+}\right. \\
& \left\{\begin{array}{l}
\sum_{j=1}^{n} a_{i j} x_{j} \leq(=, \geq) b_{i}, i=1, \cdots, m \\
\sum_{j=1}^{n} c_{i j} x_{j}+d_{i}^{-}-d_{i}^{+}=g_{i}, i=1, \cdots, l \\
x_{j} \geq 0, j=1,2, \cdots, n \\
d_{i}^{-}, d_{i}^{+} \geq 0, i=1,2, \cdots, l
\end{array}\right.
\end{aligned}
$$

The above is goal programming guiding thought which studies sports activity that is most suitable to China's community square fitness with the process being as follows.

Table 6. Goal programming data investigation table.

\begin{tabular}{|c|c|c|c|c|c|c|}
\hline & Sports Equipment & Taijiquan & Sword Dancing & Square Dancing & Running & Others \\
\hline \hline Percentage & $28.9 \%$ & $11.5 \%$ & $21.4 \%$ & $30.1 \%$ & $4.5 \%$ & $3.6 \%$ \\
\hline Satisfaction & $26.6 \%$ & $15.6 \%$ & $19.7 \%$ & $28.9 \%$ & $6.7 \%$ & $2.5 \%$ \\
\hline
\end{tabular}




\subsection{Goal Programming Data Processing}

According to the above goal programming guiding thought, data processing is carried out with community square fitness and residents' satisfaction data table, adopting sequential algorithm. Sequential algorithm is according to the priority order, transforming complicated multiple goals programming problems into multiple simple goal programming problems. Its main process is as follows:

For $k=1,2 \cdots, q$, it solves

$\min z=\sum_{j=1}^{l} P_{k}\left(\sum_{j=1}^{l} \omega^{-}{ }_{k j} d_{j}^{-}+\omega^{+}{ }_{k j} d_{j}^{+}\right)$

$\sum_{j=1}^{n} a_{i j} x_{j} \leq(=, \geq) b_{i}, i=1, \cdots, m$

$\sum_{j=1}^{n} c_{i j} x_{j}+d_{i}^{-}-d_{i}^{+}=g_{i}, i=1, \cdots, l$

$\sum_{j=1}^{l}\left(\omega_{s j}^{-} d_{j}^{-}+\omega_{s j}^{+} d_{j}^{+}\right) \leq z_{s}^{*}, s=1,2, \cdots, k-1$

$x_{j} \geq 0, j=1,2, \cdots, n$

$d_{i}^{-}, d_{i}^{+} \geq 0, i=1,2, \cdots, l$

Among them, the optimal value is $z_{k}^{*}$

At first, the most important is residents' satisfaction, therefore, its priority lists the first grade $P_{1}$; secondly, rural sports activities expansion suffering selection influences is the second grade $P_{2}$; finally, its expansion conditions also suffering community residents exercise types' influencesbecomes the third grade $P_{3}$. It is required that residents' satisfaction should be larger than $15 \%$, therefore, it gives the corresponding goal programming model:

$$
\begin{aligned}
& \min z=P_{1} d_{1}^{-}+P_{2}\left(d_{2}^{+}+d_{2}^{-}\right)+P_{3}\left(3 d_{3}^{+}+3 d_{3}^{-}+d_{4}^{+}\right) \\
& 5.7 x_{1}+3.2 x_{2}+26.4 x_{3}+11.5 x_{4}+21.4 x_{5}+28.1 x_{6}+3.6 x_{7} \\
& 7.8 x_{1}+5.4 x_{2}+25.1 x_{3}+15.6 x_{4}+19.7 x_{5}+23.9 x_{6}+2.5 x_{7}=20 \\
& x_{1}, x_{2}, \cdots, x_{i}, d_{i}^{+}, d_{i}^{-} \geq 0, i=1,2, \cdots, 7
\end{aligned}
$$

Calculating the above objective function by MATLAB software, and further from goal programming optimal solution as $z^{*}=(3,5,6)$, residents' satisfaction of $19.8 \%$ is obtained.
From the above objective function optimal solution, it can be deduced that equipment, jogging and square dance are best choices to propel community activities for further development and encourage Chinese residents to participate in sports. Residents generally have higher satisfaction with these three sports activities. The three sports activities are very simple without any strict requirement, and are fit for collective activities. Meanwhile, their technical requirements are not so high, with their influences on masses physical and psychological health being larger that conform to masses in all ages.

\section{CONCLUSION}

Firstly, the paper utilizes numerical analysis method and contrastive analysis method to analyze main features and proportions of people of China's present community fitness activities. Chinese groups demand the development of China's community square fitness activities to improve consciousness amongst groupsto pay more attention to community sports activities. Secondly, goal programming model is established to analyze main activity forms and the corresponding masses satisfaction suitable for community residents. The paper concludes that square dance is an optimal solution of goal programming, being a sports activity receiving the highest satisfaction by the masses. Further results show that square dance and other suitable collective activities are most fit for China's community sports fitness, which encourage Chinese residents to positively participate in such mutual activities.

\section{CONFLICT OF INTEREST}

The author confirms that this article content has no conflict of interest.

\section{ACKNOWLEDGEMENTS}

Declared none.

\section{REFERENCES}

[1] C. Jing-tai, F. Bing-you, and W. Ji-shuai, "A survey of residents' satisfaction degree for urban public sport services," J. Beijing Sport Univ., vol. 35, no. 6, pp. 31-34, 2009.

[2] C. Yang, and M. Ge-sheng, "An empirical study on community sports service residents' satisfaction index model," China. Sport Sci. Technol., vol. 45, no. 4, pp. 55-60, 2009.

[3] H. Ying, and X. Ming, "Theoretical and empirical study on evaluation mode of sports service satisfaction degree in city community," J. Wuhan Inst. Physical Edu., vol. 41, no. 11, pp. 40-42, 2007.

[4] L. Bao, H. Shan-lian, X. Hai-xia, and G. Jian-hui, "Indices of the equality of essential public health services in China," Chine. J. Health Pol., vol. 2, no. 6, pp. 13-17, 2009. 
[5] W. Guo-hong, and Z. Wen-hui, "Construction of the evaluation index system of city community sports: taking shanghai as an example," J. Chengdu. Physical Edu. Inst., vol. 36, no. 2, pp. 29-32, 2010.
[6] Z. Da-chao, and L. Min, "Studies on evaluation index system of public sports facilities development level in China," China Sport Sci., vol. 33, no. 4, pp. 3-23, 2013.

Received: June 10, 2015

Revised: July 29, 2015

Accepted: August 15, 2015

(C) Dayong Guo; Licensee Bentham Open.

This is an open access article licensed under the terms of the (https://creativecommons.org/licenses/by/4.0/legalcode), which permits unrestricted, noncommercial use, distribution and reproduction in any medium, provided the work is properly cited. 